\title{
Stepwise approach to functional and aesthetic full mouth rehabilitation of worn out dentition - A case report
}

\author{
Rajat Lanzara $^{1 *}$, Amit Khattak ${ }^{2}$, Anup Gopi ${ }^{3}$, Dinesh Kumar ${ }^{4}$, RK Yadav ${ }^{5}$
}

${ }^{1}$ PG Resident, ${ }^{2,3}$ Classified Specialist, ${ }^{4,5}$ Senior Specialist, Dept. of Prosthodontics and Crown \& Bridge, Army Dental Centre, Research \& Referral, Delhi Cantonment, Delhi, India

*Corresponding Author: Rajat Lanzara

Email: drrajatlanzara@gmail.com

\begin{abstract}
Prosthodontic rehabilitation is the art and science of restoring and developing form, function and aesthetics of a patient. Treatment of severe worn out dentition with surface defects require full mouth rehabilitation to restore form and function of the masticatory apparatus to as near normal as possible. Full mouth rehabilitation continues to be the biggest challenge to any clinician in Restorative dentistry. It requires efficient diagnosis and elaborated treatment planning to develop ordered occlusal contacts and harmonious articulation in order to optimize stomatognathic function, health and aesthetics which then translates to patient's comfort and satisfaction. In this case report full occlusal reconstruction of generalized attrition with loss of vertical dimension was done using segmental arch technique with reorganizing approach following Pankey Mann Schuyler philosophy. Treatment plan requires an interdisciplinary approach with periodontal and endodontic therapies to achieve acceptable esthetics and function.
\end{abstract}

Keywords: Full mouth rehabilitation, Worn out dentition, Pankey Mann Schuyler philosophy, Aesthetics, Functional rehabilitation.

\section{Introduction}

Planning and executing the restorative rehabilitation of a decimated occlusion is probably one of the most intellectually and technically demanding tasks facing a restorative dentist. Occlusal rehabilitation involves restoring the dentate or a partially dentate mouth with the aim to provide an orderly pattern of occlusal contact and articulation that will optimize oral function, occlusal stability and aesthetics. Full mouth reconstruction includes therapy which will, by improving the relationship of the teeth, improve the condition and health of the supporting structures in harmony with temporomandibular joint as well. ${ }^{1}$ Multiple philosophies are documented and used for full mouth rehabilitation. The Pankey Mann Schyuler philosophy of full mouth rehabilitation has been used for the restoration of all teeth, which is the simple and effective means of achieving treatment objectives in a segmental manner. It aims at achieving the principles of occlusion advocated by Schuyler. ${ }^{2,3}$ This case report demonstrates a successful stepwise approach to a functional full mouth rehabilitation of a worn out dentition.

\section{Case Report}

A 58 year old male reported with the chief complain of impaired mastication and unpleasing aesthetics of teeth. Past medical history revealed no significant findings while past dental history exhibit endodontic treatment of multiple teeth and extraction of bilateral lower first molars. On general examination patient was moderately built and no abnormality in temporomandibular joints. Extraoral examination show pursed lip appearance of face, loss of vertical dimension and freeway space greater than $6 \mathrm{~mm}$. Intraoral examination revealed generalized attrition with generalized fluorosis (Dean's fluorosis index - code 4) ${ }^{4}$ and missing 36, 46 teeth (Fig.1a,b). Loss of vertical dimension with reduced clinical crown length of maxillary premolars and mandibular incisor teeth was observed (Fig.1c). Diagnostic impressions, models and mounting was done to evaluate occlusion. Orthopantomograph (Fig. 1d) and routine blood investigations were completed. On the basis of history, clinical findings and investigations a diagnosis of Generalized attrition with loss of vertical dimension (Turners and Missirlian Category-I $)^{5}$ secondary to generalized fluorosis was made. Treatment plan was formulated with a multidisciplinary approach in various phases as follows:

1. Phase I - Oral prophylaxis and oral hygiene instructions.

2. Phase II - Endodontic treatment for 15, 12, 11, 21, 22, $23,24,25,34,35,42,43,44$, followed by crown lengthening in the maxillary premolar and mandibular incisor segment.

3. Phase III - Occlusal splint therapy, diagnostic mounting and complete mock wax-up at increased vertical dimension.

4. Phase IV - Prosthetic phase - Full mouth rehabilitation using Pankey Mann Schuyler philosophy.

After completion of phase I and phase II, Occlusal splint therapy was carried out by fabricating a maxillary occlusal splint to re-establish vertical dimension. A Permissive full arch occlusal splint made up of heat cured clear poly methyl methacrylate was fabricated. ${ }^{6,7}$ The occlusal splint was fabricated to incrementally restore $3 \mathrm{~mm}$ vertical dimension of occlusion (VDO) deficit. The adjustments were made according to the parameters of organic occlusion. The occlusal splint was used for 08 weeks, with regular clinical review appointments. Again a diagnostic mounting was completed and a mock wax-up was prepared at increased vertical dimension simulating the treatment plan and desired results. Following this the prosthetic phase, teeth preparation and prosthodontic rehabilitation was carried out using PMS philosophy using a segmental arch technique as follows:

1. Segment 1 - Mandibular anterior teeth

2. Segment 2 - Maxillary anterior teeth 
3. Segment 3 - Mandibular posterior teeth

4. Segment 4 - Maxillary posterior teeth

The prosthetic phase of segment 1 included teeth preparation of mandibular anterior teeth following all principles for porcelain fused to metal (PFM) crown (Fig. 2a). Gingival retraction was done using gingival retraction cord (Sure cord, India) and final impression was made using a two step polyvinyl siloxane impression with putty and light body consistency (Fig. 2b). Impression was poured with die stone (Kalabhai, India) and die preparation was performed using pindex system (Fig. 2c). Provisionalization of mandibular anterior teeth was completed (Fig. 2d) using crowns fabricated with autopolymerising polymethyl methacrylate (DPI, India).

Same procedure was followed for maxillary anterior teeth (Fig. 3a,b,c). Following provisionalization of maxillary and mandibular anterior teeth a customised anterior guidance was developed by selective alteration of provisional crowns (Fig. 3d). The objective of anterior guidance is to establish a centric stop at centric relation and a smooth glide during protrusive movement. A putty index of provisional restoration was made at this stage which was duplicated in definitive restorations. Wax pattern for metal copings were prepared using inlay wax (Renfert, Gmbh, Germany) for maxillary and mandibular anterior teeth and casting procedure was completed (Fig. 4a). Metal try-in was done on cast and in situ. Ceramic layering (Ceramco-3, Denstply, Germany) was done using putty index of provisional crowns as guide to duplicate the anterior guidance (Fig. 4b). Finishing, glazing was completed (Fig. 4c,d) and PFM crowns were cemented in-situ using glass ionomer cement (Shofu, Gmbh Germany)

For mandibular posterior teeth, Broadrick's Occlusal Plane Analyser was used to estimate an occlusal plane for mandibular posterior teeth (Fig. 5a) and a putty index of the estimated occlusal plane was made. ${ }^{8}$ Teeth preparation, final impression and provisionalization was done following all clinical protocols (Fig. 5b). The wax-up for metal copings of PFM restorations was made following the putty index guide of estimated occlusal plane (Fig. 5c). Casting, creaming layering on facial surface, finishing were completed for all mandibular posterior teeth. PFM crowns were tried on cast (Fig. 5d) and cemented in-situ using glass ionomer cement (Shofu, Gmbh Germany)

Maxillary posterior teeth were taken up for rehabilitation of maxillary posterior teeth. Teeth preparation, gingival retraction and final impression was made (Fig. 6a). The definitive restorations were fabricated using Functionally Generated Pathway (FGP). ${ }^{9}$ An acrylic template was prepared using autopolymerising polymethylmethacrylate and functional recording of mandibular movements was made using pattern resin (Fig. 6b). The FGP record was used as a guide to prepare wax pattern for definitive maxillary posterior crowns (Fig. 6c). All laboratory procedures were followed to fabricate PFM crowns (Fig. 6d) and were cemented using glass ionomer cement. Occlusion was evaluated for centric and eccentric contacts with establishment of canine guided occlusion (Fig. 7). The prosthetic rehabilitation improved aesthetics, phonetics, mastication and significantly improved the self confidence of the patient.

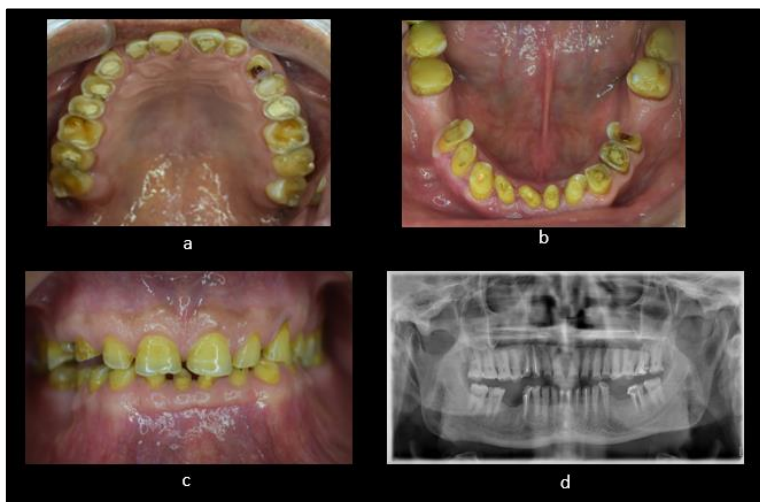

Fig. 1: Pre-treatment. a): Maxillary arch, b): Mandibular arch, c): Intraoral frontal view, d): OPG

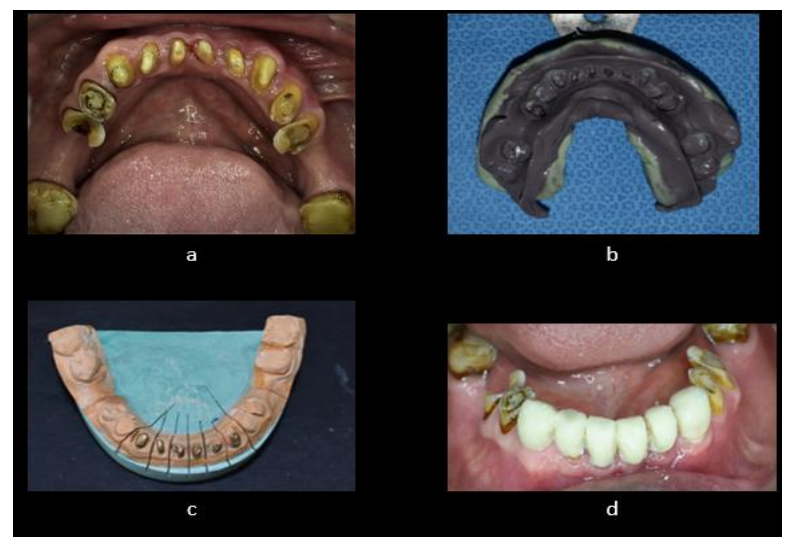

Fig. 2: Segment 1- mandibular anterior. a): Teeth preparation, b): final impression, c): Die preparation, d): Provisionalization

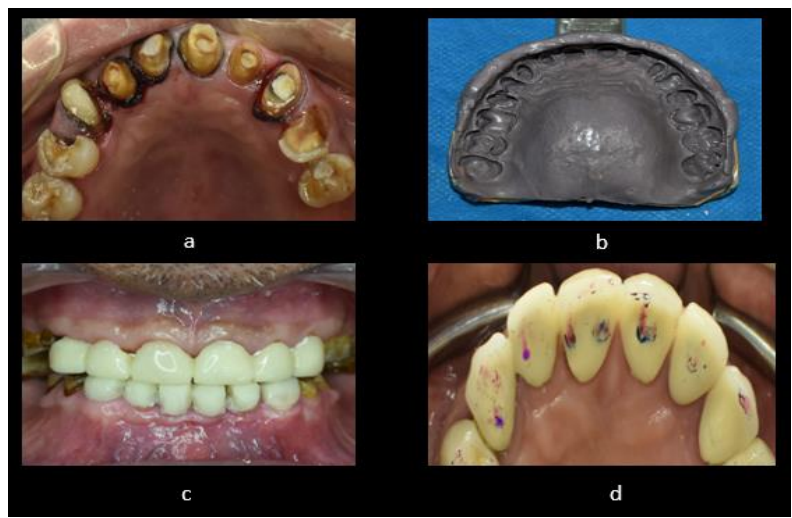

Fig. 3: Segment 2- maxillary anterior. a): Teeth preparation, b): Final impression, c): Provisionalization, d): Customized anterior guidance 


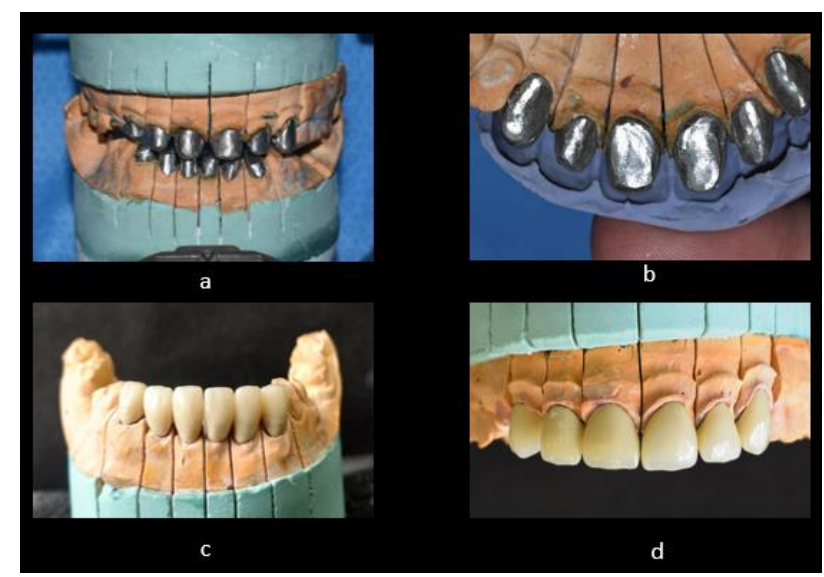

Fig. 4: a): Maxillary and mandibular anterior metal copings, b): Ceramic layering using putty index as guide, c): PFM crowns mandibular anterior, d): PFM crowns maxillary anterior.

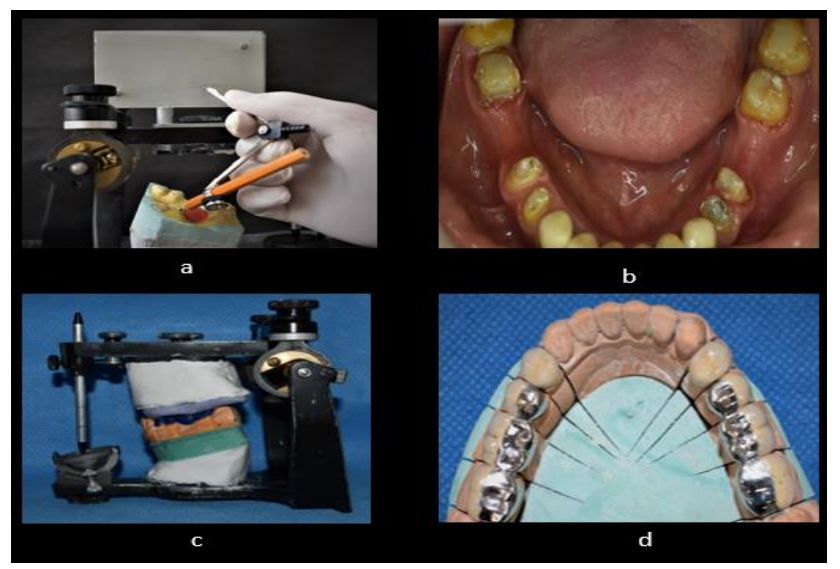

Fig. 5: Segment 3-mandibular posterior; a): Broadricks occlusal plane analysis, b): Teet preparation, c): Wax pattern prepared, d): PFM crowns mandibular posterior teeth.

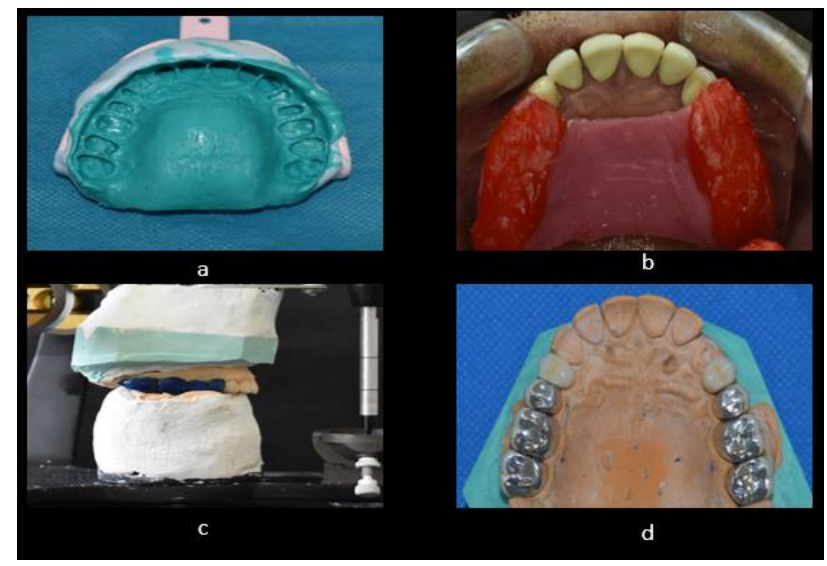

Fig. 6: Segment 4-maxillary posterior a): Final impresssion, b): FGP recording, c): Wax pattern prepared, d): PFM crowns maxillary posterior teeth.

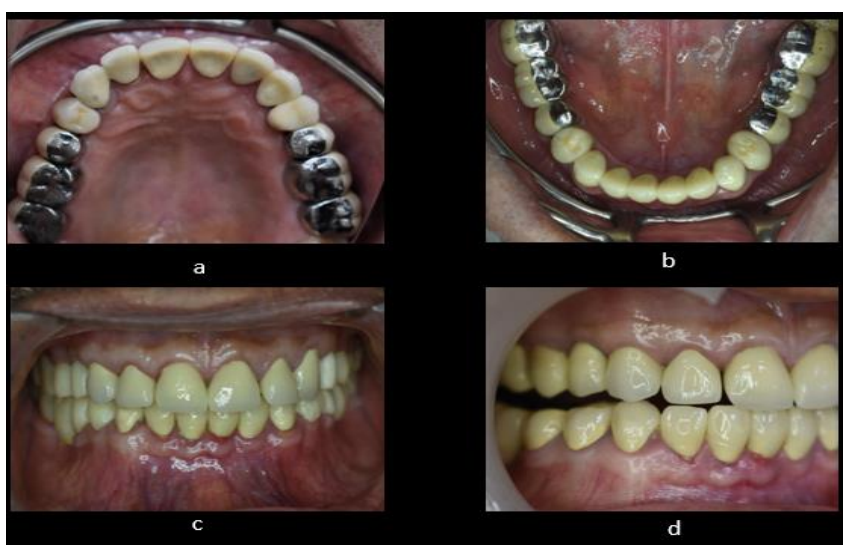

Fig. 7: Post-treatment. a): Maxillary arch, b): Mandibular arch, c): Intraoral frontal view, d): Canine guided occlusion

\section{Discussion}

Tooth wear is loss of tooth substance by means other than dental caries. Tooth wear can be because of congenital abnormalities of teeth, parafunctional habits or hypomineralisation of teeth secondary to dental fluorosis. ${ }^{10}$ Restoration of worn out dentition requires a multidisciplinary approach with cessation of parafunctional activity, endodontic intervention, periodontal therapy and in severe cases full mouth rehabilitation. Complete Mouth rehabilitation is restoration of teeth, with or without dental implants, with fixed dental protheses in the maxillae and mandible. ${ }^{11}$ It is carried out with the objective to convert all unfavorable forces on the teeth which inevitably induce pathologic conditions, into favorable forces which permit normal function and therefore induce healthy conditions. ${ }^{12}$ There are many philosophies to follow for an occlusal rehabilitation; most important among them is Hobo's philosophy and Pankey Mann Schuyler philosophy. PMS philosophy is one of the most practical philosophies for occlusal rehabilitation. It offers multiple advantages like it's a well-organized logical procedure, divides the procedure into easy lab and clinical steps, requires to prepare less than 8 teeth at a time, there is no danger of losing patient's vertical dimension, the functionally generated path and centric relation are rebuilt at the desired vertical dimension and requires no complicated instruments.

\section{Conclusion}

Abnormal occlusal conditions are overlooked in many patients because of negligence or lack of knowledge, the key to success is a multidisciplinary treatment approach. In the treatment of severely worn teeth, an anterior guidance should be established in harmony with functional jaw movements and all posterior teeth should discluded during any eccentric jaw movement. Taking the guidance into account during provisionalization, ensures minimal adjustments in the definitive restorations and greater long term predictability. PMS technique is a reliable, predictable, understandable and functional technique for a successful full mouth rehabilitation of a worn out dentition. 


\section{Source of funding}

None.

\section{Conflict of interest}

None.

\section{References}

1. Kazis H, Kazis AJ. Complete mouth rehabilitation through fixed partial denture prosthodontics. J Prosthet Dent 1960;10:296-303.

2. Dawson PE. Pankay-Mann-Schuyler philosophy of complete occlusal rehabilitaton. In: Dawson PE, editor. Evaluation Diagnosis and Treatment of Occlusal Problems. 2nd ed. Toronto: Cv Mosby Company, St. Louis Baltimore; 1989. p. 261-3.

3. Turner KA, Missirlian DM. The P.M. philosophy of occlusal rehabilitation. Dent Clin North Am 1963;7:621-38.

4. Teotia SP, Teotia.M. Endemic fluorosis in India : A challenging national health problem. J Assoc Physicians India 1994;32:347-52.

5. Turner KA, Missirlian DM. Restoration of the extremely worn dentition. J Prosthet Dent 1984;52:467-74.

6. Kirveskari P, Alanen P, Jämsä T. Association between craniomandibular disorders and occlusal interferences. $J$ Prosthet Dent 1989;62:66-9.
7. Wassell RW, Adams N, Kelly PJ. The treatment of temporomandibular disorders with stabilizing splints in general dental practice: One-year follow-up. J Am Dent Assoc 2006;137:1089-98.

8. Christopher D Lynch, Robert J Mc Connell. Prosthodontic management of the curve of spee: use of the broadrick flag. $J$ Prosthet Dent 2002;87:593-97.

9. Ash MM and Ramfjord SP. An introduction to functional occlusion, 1982, W.B. Saunders.

10. Bernard smith. Tooth wear: Aetiology and diagnosis Gerodontology Text Book 1994, 88-102 42/400.

11. Harry Shrunik. Treatment Planning For Occlusal Rehabilitation. J Prosthet Dent 1989;9:988-100 53/400.

12. Irving Goldman. The goal of full mouth rehabilitation. $J$ Prosthet Dent 1952;2:246 -51.

13. Dawson PE evaluation, diagnosis and treatment of occlusal problems, St. LOUIS CV MOSBY, 2nd edition.

How to cite this article: Lanzara R, Khattak A, Gopi A, Kumar D, Yadav RK. Stepwise approach to functional and aesthetic full mouth rehabilitation of worn out dentition A case report. Int J Oral Health Dent 2019;5(4):220-3. 